\title{
低次プロセスの直交関数による同定†
}

\author{
樋 口 清 伯・田中幸 吉 \\ 大阪大学基礎工学部。豊中市待兼山町 1 \\ (昭和 45 年 1 月 12 日 受付)
}

\section{Low Order Process Identification Using Orthonormal Function}

\author{
Seihaku Higuchi and Kokichi TanaKa \\ (Faculty of Engineering Science, University of Osaka, Toyonaka)
}

(Received January 12, 1970)

\begin{abstract}
Many methods have deen developed in consideration of the importance of identification. In the recent years the high accuracy devices such as the operational amplifier and the multiplier have been developed. Though the identification methods using analog computation have been long reported, in this paper the identification method of the low order process is treated re-evaluating the merits of analog computation.

First, the impulse response function of the process is expanded by means of orthnormal function filter, and the order of this process is decided from the discriminant which is expressed by the relation among the above expanded coefficients. For example, the form of this process is designated as the second-order lag system. At the same time, the computation rules which determine the values of the unknown parameters are also given. Finally, the approximate deviations from the true values of expansion coefficients are estimated.
\end{abstract}

\section{1. は し がき}

制御プロセスの同定に関する論文はこれまでに数多 く発表されているが1) 3), 最近はディジタル計算機の 高速性と精度の良さを生かす方向にあるとい光る。 た最適制御を行なうためにプロセスの各種の知識が要 求されるようになり，1つの大きなシステムとして取 り扱い, その解析が行なわなければならない。いっぽ ら, ここ数年来演算増幅器, 乗算器などのアナログ素 子の精度もよくなってきている.これらの素子をもち いた同定あるいは推定計算法もよく研究され2), 発表 されている.

本論文では従来取り扱われてきた方法を生かし，低 次プロセスに含ま机る未知のパラメータとその形を定 めることを考察している. 従来, 直交関数をるちいて 伝達関数を展開する方法は北森・古田氏らによって発 表されている2が，これらは主として伝達関数を直交 関数系で近似するといら立場であり, 本論文の方法は, これをさらに進めプロセスの形状決定について述べた

$\dagger$ 第 8 回計測自動制御学会学術講演会で発表 (昭 $44 \cdot 8$ )
ものである、いま対象とするプロセスを直交関数系に より展開し，この展開係数をもちいてプロセスが1次 遅れ系であるか 2 次遅れ系であるかなどの形を決定し， そのプロセスの未知パラメータを計算しようとするも のである．さらに展開係数がどのような值に収束する， かについても明らかにした。

\section{2. プロセスの直交展開}

プロセスのインパルス応答関数を $h(t)$ とすれば, それは正規直交関数系 $\left\{\varphi_{i}(t)\right\}$ をもちいてつぎのよ らに展開される．ただし時間軸を伸縮させるパラメー タ入を導入しておく.

$$
\begin{gathered}
h(t)=\sum_{0}^{\infty} a_{i} \varphi_{i}(\lambda t) \\
\lambda \int_{0}^{\infty} \varphi_{i}(\lambda t) \varphi_{j}(\lambda t) d t=\left\{\begin{array}{lll}
0 & i \neq j \\
1 & i=j & k \text { 対して }
\end{array}\right.
\end{gathered}
$$

(2) 式によって展開係数 $a_{i}$ は,

$$
a_{i}=\int_{0}^{\infty} h(t) \varphi_{i}(\lambda t) d t
$$

となる。

㨁交関数系をどのような基準で選択するか，さらに 
は式の展開はとうぜん有限項で打切らなければならな いが，その項数の定め方なぞは重要であるが，ひじょ らにむずかしい問題である。 これについては 5. で再 びられる、いち括ら従来の結果から回路実現の容易さ

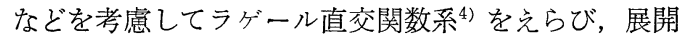
項数は $L$ する. ラゲール直交関数系扤よびそのラプ ラズ変換はそれぞれつぎのようになる。

$$
\begin{gathered}
\varphi_{i}(\lambda t)=\frac{\sqrt{\lambda}}{i !} e^{\lambda t / 2} \frac{d^{i}}{d(\lambda t)^{2}}\left\{(\lambda t)^{i} e^{-\lambda t}\right\} \\
\Phi_{i}(s)=\mathcal{L}\left[\varphi_{i}(\lambda t)\right]=\frac{\sqrt{\lambda}}{s+\lambda / 2}\left(\frac{s-\lambda / 2}{s+\lambda / 2}\right)^{i}
\end{gathered}
$$

ここで， $\mathcal{L}[$ ] はラプラス変換を意味する.'

(3) 式の展開係数 $a_{\imath}$ を実際のプロセスに対して求め る方法を考える. 以下では (1)式の右辺で表わされて いるように直交関数系 $\left\{\varphi_{i}(t)\right\}$ の 1 次結合で表わされ るるのを值交フィルタとよぶことにし，これを Fig. 1

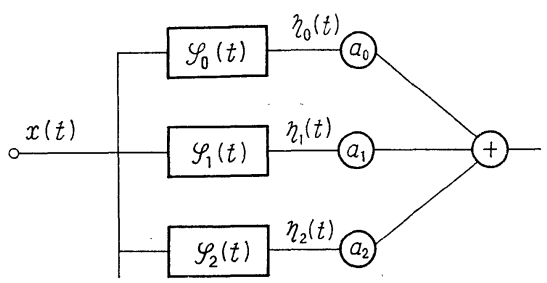

Fig. 1 Block diagram of orthonormal filter

に示す。係数 $a_{i}$ はプロセスと直交フィルタとの出力 差の自乗（平均值）を最小にするように最急降下法あ るいはその変形した方法によって定める，プロセスへ の入力を, $x(t)$, 出力を $y(t)$, 直交フィルタの各要 素の出力を $\eta_{i}(t)$ とすれば係数計算式はつぎのように なる。

$$
\begin{array}{r}
\frac{d a_{i}(t)}{d t}=-k \eta_{i}(t) \varepsilon(t) \quad \begin{array}{c}
(\text { 最急降下法 }) \\
(i=0,1, \cdots(L-1))
\end{array} \\
\frac{d a_{i}(t)}{d t}=-k \eta_{i}(t) \operatorname{sgn}(\varepsilon(t)) \quad((6) \text { 式の変形 }) \\
(i=0,1, \cdots(L-1))
\end{array}
$$

ここで,

$$
\begin{aligned}
\varepsilon(t) & =\sum_{0}^{L-1} a_{i} \eta_{i}(t)-y(t) \\
\eta_{i}(t) & =\int_{0}^{\infty} \varphi_{i}(\lambda \tau) x(t-\tau) d \tau \\
y(t) & =\int_{0}^{\infty} h(\tau) x(t-\tau) d \tau \\
\operatorname{sgn}(\varepsilon) & =\left\{\begin{array}{rrr}
1 & \varepsilon \geq 0 & \text { のとき } \\
-1 & \varepsilon<0 & \text { のとき }
\end{array}\right.
\end{aligned}
$$

$k$ は収束の速さに関係する任意の正の定数である.

(6)，（7)式で与兄られる計算式をもちいた係数測定

回路を Fig. 2 に示す. スイッチ $\mathrm{sw} 1, \mathrm{sw} 2, \cdots を \mathrm{~A}$

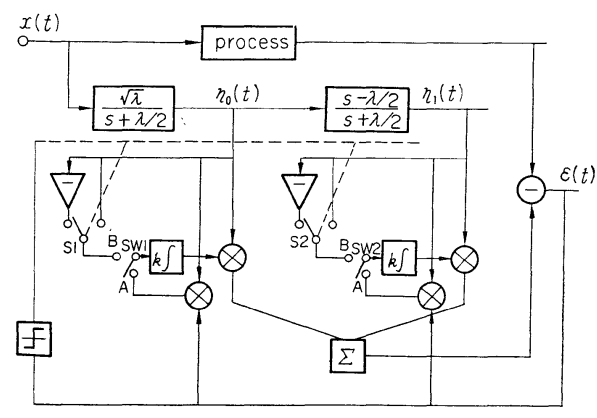

Fig. 2 Block diagram of measurement circuit

側に倒したときには $(6)$ 式の最急降下法の計算を行な い，B側にしたときには（7）式に相当する。な特 $\mathrm{s} 1, \mathrm{~s} 2, \cdots$ は $\operatorname{sgn}(\varepsilon(t))$ によってオンオフする.これ ら 2 つ計算法は後述するが，本質的には同じである. しかし(7)式の計算式に従った活らが乗算器が半分と 少なくそれだけ収束に和ける誤差も小さくなる利点が ある。

\section{3. 展開係数とプロセスのパラメータの 決定}

\begin{tabular}{|c|c|c|}
\hline trans. fun. & imp. resp. & expansion coefficient \\
\hline$\frac{1}{s+\alpha}$ & $e^{-\alpha t}$ & $a_{i}=\frac{\sqrt{\lambda}}{\alpha+\lambda / 2}\left(\frac{\alpha-\lambda / 2}{\alpha+\lambda / 2}\right)^{i}$ \\
\hline$\frac{1}{(s+\alpha)^{2}}$ & $t e^{-\alpha t}$ & $\begin{aligned} a_{i}=\sqrt{\lambda} & \frac{(\alpha-\lambda / 2)^{t-1}}{(\alpha+\lambda / 2)^{i+2}} \\
& \times\{\alpha-(2 i+1) \lambda\}\end{aligned}$ \\
\hline$\frac{1}{(s+\alpha)^{3}}$. & $\frac{1}{2} t^{2} e^{-\alpha t}$ & $\begin{aligned} a_{i}= & \sqrt{\lambda} \frac{(\alpha-\lambda / 2)^{i-3}}{(\alpha+\lambda / 2)^{i+3}} \\
& \times\left\{\alpha^{2}-2(2 i+1) \alpha\right. \\
& \left.+\left(2 i^{2}+2 i+1\right) \lambda^{2}\right\}\end{aligned}$ \\
\hline$\frac{1}{(s+\alpha)^{2}+\omega^{2}}$ & $e^{-\alpha t} \sin \omega t$ & $\begin{aligned} a_{i}= & \frac{\sqrt{\lambda}}{\omega} \frac{\sin ^{i+1} \theta_{1}}{\sin ^{i} \theta_{2}} \\
& \times \sin \left\{(i+1) \theta_{1}-i \theta_{2}\right\}\end{aligned}$ \\
\hline$\frac{1}{(s+\alpha)(s+\beta)}$ & $\frac{1}{\beta-\alpha}\left(e^{-\alpha t}-e^{-\beta t}\right)$ & $\begin{aligned} a_{i} & =\frac{1}{\beta-\alpha}\left\{\frac{\sqrt{\lambda}}{\alpha+\lambda / 2}\right. \\
& \times\left(\frac{\alpha-\lambda / 2}{\alpha+\lambda / 2}\right)^{2}-\frac{\sqrt{\lambda}}{\beta+\lambda / 2} \\
& \left.\times\left(\frac{\beta-\lambda / 2}{\beta+\lambda / 2}\right)^{i}\right\}\end{aligned}$ \\
\hline
\end{tabular}

種々のプロセスのインパルス応答関数に対する展開 係数 $a_{i}$ は(3)式によって計算することができ，その 結果が Table 1 飞まとめてある。，さらに 2. で測定 された展開係数 $a_{i}$ をもちいてプロセスがたと党ば 1 次遅れ系であるのか， 2 次遅れ系なのかという形を定 めるためには判定式が必要となるが，1つの計算例を 示すとつぎのようにして求められる.

1 次遅れ系 $\frac{1}{s+\alpha}$ のとき

Table 1 Some examples of expansion coefficients

where $\theta_{1}=\tan ^{-1} \omega /(\alpha+\lambda / 2), \theta_{2}=\tan ^{-1} \omega /(\alpha-\lambda / 2)$ 
Table 1 から

$$
a_{i}=\frac{\sqrt{\lambda}}{\alpha+\lambda / 2}\left(\frac{\alpha-\lambda / 2}{\alpha+\lambda / 2}\right)^{i}
$$

これから，

$$
\begin{aligned}
& \frac{a_{i+1}}{a_{i}}=\left(\frac{\alpha-\lambda / 2}{\alpha+\lambda / 2}\right) \\
& \frac{a_{i+2}}{a_{i+1}}=\left(\frac{\alpha-\lambda / 2}{\alpha+\lambda / 2}\right)
\end{aligned}
$$

となり $\frac{a_{i+1}}{a_{i}}=\frac{a_{i+2}}{a_{i+1}}$ とおいて $a_{i+1}{ }^{2}-a_{i} a_{i+2}=0$

したがって, 判定式,

$$
D=a_{i+1}^{2}-a_{i} a_{i+2}
$$

が求まる. 展開係数の間で(14)式で示す判定式 $D$ が 0 になるときは 1 次遅れ系と決定する。同様な計算を他 の例について求めてまとめたものが Table 2 である. この Table 2 で 1 次遅れ系と同じ判定式をもつもの が 1 つり，それの伝達関数は $1 / s$ である. もらろん この場合にはすべての展開係数 $a_{i}$ の絶対值が等しい といら別の特徵をもっている. つぎに(14)式の判定式 によってどのようなプロセスであるかが定まったとさ にはそのプロセスに含まれる未知のパラメータを測定 值から計算しなければならない。このパラメータ計算 式をまとめたものが Table 3 である. 以上の結果を るちいると低次の主要なプロセスについて実験を行な うことができ，その結果をまとめると Table 4 とな る.

\begin{tabular}{|c|c|}
\hline trans. fun. & parameters \\
\hline$\frac{K}{s+\alpha}$ & $\alpha=\frac{\lambda}{2} \frac{a_{0}+a_{1}}{a_{0}-a_{1}} \quad \dot{K}=\frac{a_{0}^{2}}{a_{0}-a_{1}}$ \\
\hline$\frac{K}{(s+\alpha)^{2}}$ & $\alpha=\frac{\lambda}{2} \frac{3 a_{0}+a_{1}}{a_{0}-a_{1}} \quad K=\frac{4 \lambda^{2} a_{0}^{3}}{\left(a_{0}-a_{1}\right)^{2}}$ \\
\hline$\frac{K}{(s+\alpha)^{2}+\beta^{2}}$ & $\begin{aligned} \alpha & =\frac{\lambda}{2} \frac{a_{0} a_{1}-a_{0} a_{2}+a_{1}^{2}-a_{0}^{2}}{a_{0} a_{2}-a_{1}^{2}} \\
\beta & =\frac{\lambda}{2} \frac{a_{0} P_{1}}{a_{1}^{2}-a_{0} a_{2}} \quad K=\frac{2 \lambda a_{0}^{2}}{P_{1}}\end{aligned}$ \\
\hline$\frac{K}{(s+\alpha)(s+\beta)}$ & $\begin{array}{l}\alpha=\frac{\lambda}{2} \frac{3 a_{0}+a_{1}-P_{2}}{a_{0}-a_{1}+P_{2}} \\
\beta=\frac{\lambda}{2} \frac{3 a_{0}+a_{1}+P_{2}}{a_{0}-a_{1}-P_{2}}\end{array} \quad K=\frac{\lambda a_{0}^{2}}{P_{2}}$ \\
\hline \multicolumn{2}{|c|}{$\begin{array}{ll}\text { where } & P_{1}=\left(3 a_{1}^{2}+2 a_{0} a_{1}-a_{0}^{2}-4 a_{0} a_{2}\right)^{1 / 2} \\
& P_{2}=\left(a_{0}^{2}+4 a_{0} a_{2}-2 a_{0} a_{1}-3 a_{1}^{2}\right)^{1 / 2}\end{array}$} \\
\hline
\end{tabular}

Table 2 Some examples of discriminant

\begin{tabular}{c|l}
\hline trans. fun. & \multicolumn{1}{|c}{ discriminant $D$} \\
\hline$\frac{K}{s+\alpha}$ & $D_{1}=a_{i} a_{i+2}-a_{i+1}{ }^{2} \quad i \geq 0$ \\
\hline$\frac{K}{(s+\alpha)^{2}}$ & $D_{11}=4 a_{0} a_{2}-\left(a_{0}+a_{1}\right)\left(3 a_{1}-a_{0}\right)$ \\
\hline$\frac{K}{(s+\alpha)^{2}+\beta^{2}}$ & $D_{22}=a_{1}\left(a_{0} a_{3}+a_{1} a_{2}\right)-\left(a_{0}+a_{1}\right)\left(a_{0} a_{2}-a_{1}{ }^{2}\right)$ \\
\hline$\frac{K}{(s+\alpha)(s+\beta)}$ & $D_{23}=\left(a_{0}+a_{1}\right)\left(a_{0} a_{2}-a_{1}{ }^{2}\right)-a_{0}\left(a_{0} a_{3}-a_{1} a_{2}\right)$ \\
\hline
\end{tabular}

Table 3 Computation rules of process parameter
Table 4 Some examples of identified process

\begin{tabular}{c|c|c}
\hline trans. fun. & \multicolumn{2}{|c}{ calculated examples } \\
\hline$\frac{1}{s+1}$ & $\frac{0.96}{s+0.97}(\lambda=0.3)$ & $\frac{1.00}{s+1.06} \quad(\lambda=1.0)$ \\
\hline$\frac{0.7}{s+0.5}$ & $\frac{0.68}{s+0.48} \quad(\lambda=0.6)$ & $\frac{0.7}{s+0.49} \quad(\lambda=0.8)$ \\
\hline$\frac{1}{s^{2}+3 s+2}$ & $\frac{1.19}{s^{2}+3.16 s+2.13}(\lambda=0.8)$ & $\frac{1.09}{s^{2}+3.05 s+1.9} \quad(\lambda=1)$ \\
\hline$\frac{1}{(s+1)^{2}}$ & $\frac{0.95}{(s+0.92)^{2}}(\lambda=0.8)$ & $\frac{0.97}{(s+1.08)^{2}}(\lambda=1)$ \\
\hline
\end{tabular}

この実験に拈いては入力 $x(t)$ として白色雑音（ク ロック周波数を $150 \mathrm{~Hz}$ にとった 20 段のシフトレジ スタによる発生される $M$ 系列雑音）を低域ろ波器（そ の伝達関数 $1 /(s+0.5))$ に通したものを利用した。 本論文で提案すると同定方法は以上のようであるが, 以下これらの定量的検討を行なら.

\section{4. 推定計算の収束値の検討}

展開係数を求める方法として $(6),(7)$ 式の計算式 を用いたが，これらの計算式は本質的に安定であり， その収束值がどのような值になるかを検討しておけば よい.この章ではプロセスのインパルス応答関数はつ ぎの $\left(1^{\prime}\right)$ 式で記述されるものとする.

$$
h(t)=\sum_{0}^{L-1} a_{d i} \varphi_{i}(\lambda t)+\sigma(t)
$$

ここで, $\sigma(t)$ は $L$ 個の展開係数をもちいて記述され なかった成分を表わす。まず（6)式で $x(t)$ が平均值 0 の白色雑音であるとし $\varepsilon^{2}$ を最小にする. 以後の議 論では $x(t)$ の定常性を仮定する.（6)，（7)式の微 分方程式は非定常で厳密には確率微分方程式の形をと るが，これを避けてつぎのような方法で収束值を評価 する.（6) 式の微分方程式に正規性見本過程 $x(t)$ の 要素を加え時刻 $t$ で観測することによって $a_{i}(t)$ を求 める実験を同一初期值について繰り返す。このように して得られる $a_{i}(t)$ の集合を想定し，この平均值を調 ベる，記述を簡単にするため $\overline{a_{i}(t)}$ (一は平均操作を 表わす）を $a_{i}(t)$ とかさ， $\lambda=1$ とすると $(6)$ 式から，

$$
\begin{aligned}
\frac{d a_{i}(t)}{d t} & =-k\left[\sum_{j=0}^{L-1} a_{j}(t) \int_{0}^{\infty} \int_{0}^{\infty}\right. \\
& \times \varphi_{i}(\tau) \varphi_{j}(\omega) \overline{x(t-\tau) x(t-\omega)} d \tau d \omega \\
& \left.-\int_{0}^{\infty} \int_{0}^{\infty} \varphi_{i}(\omega) h(\tau) \overline{x(t-\tau) x(t-\omega)} d \tau d \omega\right]
\end{aligned}
$$

(15)式を導くには各変数は正規性確率変数であるとし, $\overline{x(t)}=0$ としてある.

*1 正規性確率変数 $x, y, z$ に関する平均操作についてつぎ の関係式をもちいた。

$$
\overline{x y z}=\overline{x y} \cdot \bar{z}+\overline{x y} \cdot \bar{y}+\overline{y z} \cdot \bar{x}-2 \bar{x} \cdot \bar{y} \cdot \bar{z}
$$


ここで $a_{i}(t)$ が正規性確率変数としているが，これ は (6)式をつぎのように変形し，近似したものである. まず， $h(\tau)=\sum_{j=0}^{L-1} a_{d j} \varphi_{j}(\tau)$ と拉き， $a_{i}(t)-a_{d i}=b_{i}(t)$ と変数変換すると,

$$
\frac{d b_{i}(t)}{d t}=-k \sum_{j=0}^{L-1} b_{j}(t) \eta_{i}(t) \eta_{j}(t)
$$

さらに時刻 $t$ 固定して，

$$
b_{i}(t+\Delta t)=b_{i}(t)-k \Delta t \sum_{j=0}^{L-1} b_{j}(t) \eta_{i}(t) \eta_{j}(t)
$$

之する. $\eta_{i}(t)(i=0,1, \cdots,(L-1))$ は正規性確率変数 であるが必ずしもこれら相互間の相関は 0 でない，い ま $\phi_{i j}(t)=\eta_{i}(t) \eta_{j}(t)$ とすると確率密度関数 $P\left(\phi_{i j}\right)$ はつぎのように与えられる8

$$
P\left(\phi_{i j}\right)=\frac{1}{\pi \sqrt{1-\rho^{2}}} \exp \left(\frac{\rho\left|\phi_{i j}\right|}{1-\rho^{2}}\right) K_{0}\left(\frac{\left|\phi_{i j}\right|}{1-\rho^{2}}\right)
$$

$\rho$ は正規化された相関係数, $K_{0}(\cdot)$ は変形ベッセル関 数である. 時間を $t$ に固定しているので省略した.

この $P\left(\phi_{i j}\right)$ は $\left|\phi_{i j}\right|$ が大きいところで少しはずれ るが，正規分布で近似することができる. $\eta_{i}(t)(i=0$, $1, \cdots)$ 相互間の相関係数が小さいとさには $b_{i}(t)$ を固 定して考光ると $b_{i}(t+\Delta t)$ 怔正規性確率変数之近似で きる。特に相関がなければひじょうによい近似である ことが知られている ${ }^{8)}$.このことから $a_{i}(t)$ を正規性 確率変数とみなしている. (15) 式に $\overline{x(t-\tau) x(t-\omega)}$ $=\delta(\tau-\omega)$ の関係をるちい $h(t)$ の第 $i$ 番目の展開係 数 $a_{d \imath}$ を使って書き直すと，

$$
\frac{d a_{i}(t)}{d t}=-k a_{i}(t)+k a_{d i} \quad(i=0,1, \cdots, L-1)
$$

これから，

$$
a_{i}(t)=a_{d i}\left(1-e^{-k t}\right) \quad(i=0,1, \cdots, L-1)
$$

となり $\left(1^{\prime}\right)$ 式のように $\sigma(t)$ があるときでる $t \rightarrow \infty$ と なれば展開係数の個数 $L$ に相当する係数だけは正しく $a_{d i}$ と求まることがわかる.つぎに有色雑音の場合に ついて考察する. (15)式を求めたと同じ考方方から.

$$
\begin{aligned}
& \frac{d a_{i}(t)}{d t}=-k\left[\sum_{j}^{L-1} a_{j}(t) \int_{0}^{\infty} \int_{0}^{\infty}\right. \\
& \quad \times \varphi_{i}(\tau) \varphi_{j}(\omega) \overline{x(t-\tau) x(t-\omega)} d \tau d \omega \\
& \left.\quad-\int_{0}^{\infty} \int_{0}^{\infty} \varphi_{i}(\omega) h(\tau) \overline{x(t-\tau) x(t-\omega)} d \tau d \omega\right]
\end{aligned}
$$

そなり，(1') 式をもちいると，

$$
\begin{aligned}
& \frac{d a_{i}(t)}{d t}=-k\left[\sum_{j}^{L-1}\left(a_{j}(t)-a_{d j}\right) \int_{0}^{\infty} \int_{0}^{\infty}\right. \\
& \quad \times \varphi_{i}(\omega) \varphi_{j}(\tau) \overline{x(t-\omega) x(t-\tau)} d \tau d \omega \\
& \left.\quad-\int_{0}^{\infty} \int_{0}^{\infty} \sigma(\tau) \varphi_{i}(\omega) \overline{x(t-\tau) x(t-\omega)} d \tau d \omega\right]
\end{aligned}
$$

（18）式を行列で表示すれば,

$$
\frac{d a(t)}{d t}=-k Q\left(a(t)-a_{d}\right)+k \delta
$$

ここで,

$a(t)=\left[a_{0}(t), a_{1}(t), \cdots, a_{L-1}(t)\right]^{T}$,

$a_{d}=\left[a_{d 0}, a_{d 1}, \cdots, a_{d L-1}\right]^{T}$

$\dot{\delta}=\left[\sigma_{0}, \sigma_{1}, \cdots \sigma_{L-1}\right]^{T}$

$\sigma_{i}=\int_{0}^{\infty} \int_{0}^{\infty} \sigma(\tau) \varphi_{i}(\omega) \overline{x(t-\tau) x(t-m)} d \tau d \omega$

$Q=\left\{q_{i j}=\int_{0}^{\infty} \int_{0}^{\infty} \varphi_{i}(\omega) \varphi_{j}(\tau) \overline{x(t-\tau) x(t-\omega)} d \tau d \omega\right\}$

(19)式に $w=a-a_{d} w(0)=-a_{d}$ なる变数变換を行な い， $\delta=0$ とす机ば，

$$
\frac{d w(t)}{d t}=-k Q w(t) \quad w(0)=-a_{d}
$$

となりQは正定 (positive definite) であるからつぎ の不等式）をるちいることができる．通常，Qは非負 であるが正定值としてもとの適用範团はあまり制限さ

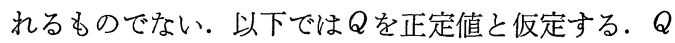
の最大特よび最小の固有值を $\Lambda_{e}, \Lambda_{s}$ とすれば，

$$
\begin{aligned}
&\|w(t)\| \leqq\|w(0)\| \exp \left[-\int_{0}^{t} \Lambda_{s} d t^{\prime}\right] \\
& \text { ここで, }\|w\|=(w, w)^{1 / 2}
\end{aligned}
$$

であり $\lim _{t \rightarrow \infty}\|w(t)\|=0$ となる. いっぽう， $\sigma(t) \neq 0$ のときには解析は困難であるが，（7 式をるちいたと きの解析の結果から調べてみる.

（7）式を解くため，近似として(15)式を求めたと同 じ議論をすることにより初期值 0 から出発したとき時 刻 $t$ に打ける $a_{i}^{\prime}(t)$ の集合を想定し，その平均值を求 める方法 ${ }^{5}$ による。（7)式から，

$$
\frac{d a_{i}(t)}{d t}=-k \overline{\eta_{i} \operatorname{sgn}(\varepsilon)}
$$

$k$ が十分小さいときには $a_{i}(t)$ は定常過程とみなすこ とができ， $x(t)$ が正規性であるから $\eta_{i}, \varepsilon$ は正規性確 率変数である.また $a_{i}(t)$ についてはすでに述べた相 関のある場合と同じようにして近似的に正規性確率変 数とみなすことにする.このときには，

$$
\begin{aligned}
\overline{\eta_{i} \operatorname{sgn}(\varepsilon)} & =2 \int_{-\infty}^{\infty} d \eta_{i} \int_{0}^{\infty} \varepsilon p\left(\eta_{i}, \varepsilon\right) d \varepsilon \\
& =\sqrt{\frac{2}{\pi}} \rho
\end{aligned}
$$

ここで,

$$
\rho=\frac{\overline{\varepsilon(t) \overline{\eta_{i}(t)}}}{\overline{\left[\varepsilon^{2}(t)\right]^{1 / 2}}}
$$

(8)，(10) 式をるちいて, $\sigma(t) \neq 0$ から $\overline{\varepsilon^{2}(t)} \neq 0$. で あるから，

$$
\rho=\frac{1}{\left[\overline{\varepsilon^{2}(t)}\right]^{1 / 2}}\left(\sum_{j}^{L-1} a_{j}(t) \overline{\eta_{i}(t) \eta_{j}(t)}-\overline{\eta_{i}(t) y(t)}\right)
$$


これから(23)式は，

$$
\frac{d a_{i}(t)}{d t}=-k^{\prime}(t)\left(\sum_{j=0}^{L-1} a_{j}(t) \overline{\eta_{i}(t) \eta_{j}(t)}-\overline{\eta_{i}(t) y(t)}\right)
$$

$$
\text { ここで, } k^{\prime}(t)=\sqrt{\frac{2}{\pi}} \frac{1}{\left(\varepsilon^{2}(\bar{t})\right)^{1 / 2}}
$$

(24)式に(1')式をもちい行列表示すれば,

$$
\frac{d a(t)^{\prime}}{d t}=-k^{\prime}(t) Q\left(a(t)-a_{d}\right)+k^{\prime}(t) \delta, \quad a(0)=0
$$

$$
\text { ここで, }
$$

$a(t)=\left[a_{0}(t), a_{1}(t), \cdots, a_{L-1}(t)\right]^{T}$,

$a_{d}=\left[a_{d 0}, a_{d 1}, \cdots, a_{d L-1}\right]^{T}, \delta=\left[\sigma_{0}, \sigma_{1}, \cdots \sigma_{L-1}\right]^{T}$

$\sigma_{i}=\int_{0}^{\infty} \int_{0}^{\infty} \sigma(\tau) \varphi_{i}(\omega) \overline{x(t-\tau) x(t-\omega)} d \tau d \omega$

$Q=\left\{q_{i j}=\int_{0}^{\infty} \int_{0}^{\infty} \varphi_{i}(\omega) \varphi_{j}(\tau) \overline{x(t-\tau) x(t-\omega)} d \tau d \omega\right\}$

(25)式に和いて $a(t)-a_{d}=w(t)$ 之変数変換を行なう と,

$$
\frac{d w(t)}{d t}=-k^{\prime}(t) Q w(t)+k^{\prime}(t) \delta, \quad w(0)=a_{d}
$$

$U Q U^{T}=\Lambda$ となる対角化変換 $U$ を(27)式に作用させ て $U w(t)=u(t) \quad U \delta=\rho$ と打けば,

$$
\frac{d u(t)}{d t}=-k^{\prime}(t) A u(t)+k^{\prime}(t) \rho \quad u(0)=U a_{d}
$$

$Q$ は雑音を直交フィルタに加えたときの出力の共分散 行列であり，行列 $A$ は正の固有值をもつ対角行列で ある.（28）式の平衡点での值 $u(\infty)$ はつぎのように なる。

$$
u_{i}(\infty)=\rho_{i} / \lambda_{i}
$$

ここで， $u_{i}(\infty)$ はベクトル $u(\infty)$ の第 $i$ 成分であり, $\lambda_{i}$ は対角行列 $\Lambda$ の第 $(i, i)$ 成分である. ここで $u_{i}$ $\frac{\rho_{i}}{\lambda_{i}}=v_{i}$ と和けば(28)式から，

$$
\frac{d v(t)}{d t}=-k^{\prime}(t) v
$$

いま正值対称行列 $P$ をちいて $V=v^{T}(t) P v(t)$ を作 ると, これは平衡点 0 から $u(t)$ までの距離に相当し ている.これから，

$$
\frac{d V}{d t}=2\left(\frac{d v(t)}{d t}-\right)^{T} P v(t)=-2 k^{\prime}(t) v(t)^{T} P v(t) \leqq 0
$$

となりつねと平衡点 0 に収束する，等号が成分するの は $v(t)=0$ のときのみである. (29)式を逆変換すると，

$$
U^{T} u(\infty)=U^{T} \Lambda^{-1} \rho
$$

となりけけっきょくつぎのようになる。

$$
w(\infty)=Q^{-1} \delta
$$

ここで肩の $(-1)$ は逆行列を表わす.
(25)式の微分方程式が正しい解に収束するためには 変数変換した $(27)$ 式に执いて $w(t) \rightarrow 0$ となることで ある、ところが(30)式は有限の值をもつためかたよっ た収束になっている。このかたよりは $L$ だをさなれ ば $\sigma(\tau) \rightarrow 0$ となり $(30)$ 式に称いて $(w) t \rightarrow 0$ となる. あるいは直交関数系 $\left\{\varphi_{i}(\lambda t)\right\}$ の時間パラメータ入を 適当に兄らぶことにより $L$ 個でも $\sigma(\tau)$ を小さくする ことが可能である．実際にオフラインで同定するとき には 3. でプロセスの未知パラメータの計算に使用す る展開係数が数個であるなら, 行列 $Q$ を直接測定しそ の逆行列を評価することにより(30)式から，近似的に 補正することも可能である.

\section{5. 展開係数の個数と直交関数系の選択}

4. で述べたように展開係数の個数は推定精度と重 要な関係をもつ，Lが大きくなり $\sigma(t)=0$ とみなしう るときには測定される係数値は正しいとできるが，実 際にLを大きくすると，それぞれの係数は有意でない 值をもつことになる。それは有限時間で測定すれば， すなわちデータ長が一定であるとしたとき展開係数が 増すと各係数の分散が増し, 本来 0 であるべき係数る 0 とは測定されない.この結果, 係数が 0 でないという ことが有意であると結論できないことが起こるためあ まり展開係数の個数を多くとると全体の分散が大きく なり好ましくない，これを避ける方法としてはLを固 定して $\sum_{0}^{L-1} a_{i}{ }^{2}$ が大きくなるように直交関数系のパラ メータ入をえらぶことである.ラゲール直交関数系は ポテンショメータを可変にすることにより容易に入を 変えることができる，これを Fig. 3 亿示す。この Fig. 3 亿は 1 つのブロックのみを示したが連動ポテ ンショメータによりきわめて簡単に，また装䈯として もサーボモータにより自動化することも可能である.

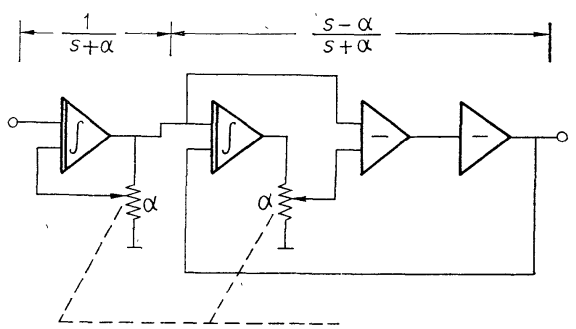

Fig. 3 Orthonormal filter with variable parameter

直交関数系としては他に多くのものがあるが，区間 $(0, \infty)$ で直交するものとしてはラゲール直交関数系と 比較して特にすぐれたものはいまのところ見当たらな い. 少し異なったものとして有限区間 $(0, T)$ で直交す 
る関数系としてアダマール行列から作られる Walsh 関数列があり，これを利用した同定問題については現 在検討中である.つぎに問題になるのは各展開関数が プロセスの変化汇対してどのように変化するか，いわ ゆる感度の問題である. 簡単な例についての実験結果 を示すと Fig. 4 となる. この実験はラゲール直交関 数系についてのみ行なったのであるが，入が比較的大 きいときには係数值の変化も顕著になっているが，実 際にはどのような入をもちいればよいかは個々の対象 に応じて決められる必要があり一概には論じられない。

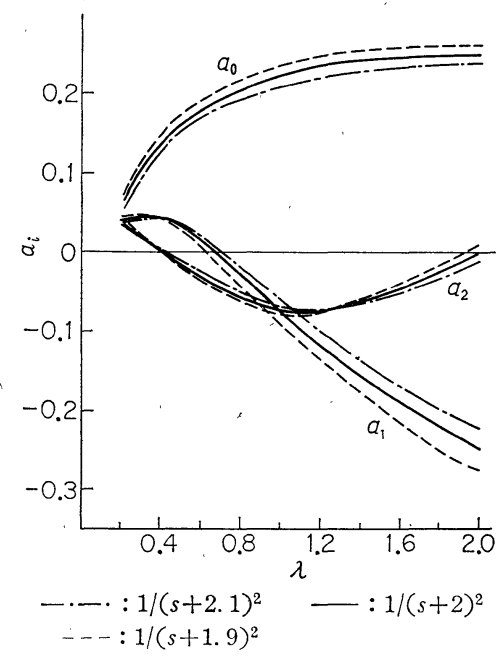

Fig. 4 Sensitivity for process parameter variation

つぎにプロセスの伝達関数に含をれるパラメータを 変化させたとき判定式の值がどのように変化するかを 調べてみよう。一例としてつぎのような簡単な次遅れ 系を採り上げる*2.

$$
\left[\begin{array}{l}
\dot{x} \\
\mu \dot{z}
\end{array}\right]=\left[\begin{array}{cr}
-1 & 1 \\
0 & -1
\end{array}\right]\left[\begin{array}{l}
x \\
z
\end{array}\right]+\left[\begin{array}{l}
0 \\
1
\end{array}\right] u
$$

ここで, $u$ は制御入力, $\mu$ がパラメータで, $x, z$ は状 態変数である. $\mu=0$ のときには 1 次遅れ系， $\mu \neq 0$ のときは 2 次である。いま $\mu=0$ の近傍に和ける $D_{1}$, $D_{22}$ 特よび $D_{23}$ の值を Fig. 5 に示す. $D_{21}$ につい てはこのスケールでははずれるため記入していない. この Fig. 5 からみても感度はかなり良いと思われる.

\section{6. 本方法の適用条件の検討}

ラゲール直交関数系は ( 5 ) 式からも明らかなよらに 位相推移器とみられる.したがって, ある周波数の正弦 波が入力 $x(t)$ として加えられるとプロセスの位相推 移と同程度の位相推移をもった $\eta_{j}(t)$ があると，この

*2 この例はつぎの論文から採用した. P. V. Kokotovic \& P. Sannuti; IEEE Trans. on AC, AC-13-4 (1968)

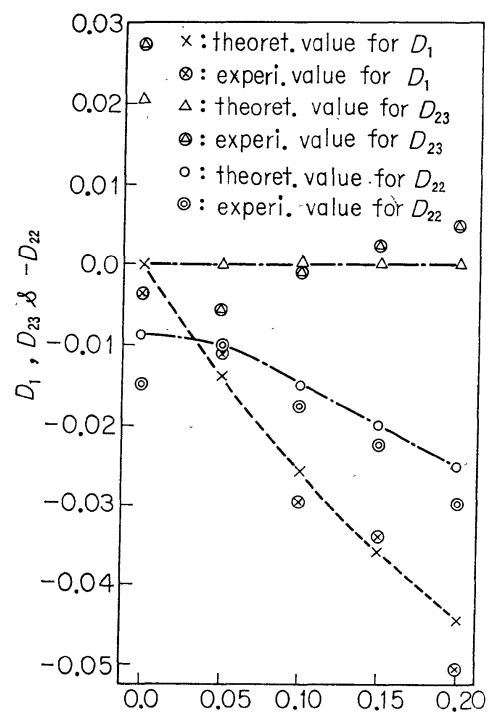

Fig. 5 Sensitivity of discriminants $D_{1}, D_{23}$ $\& D_{22}$ for process parameter $\mu$

係数だけが大きくなり，いわゆる特定周波数に対する 定常応答の解析になってしまう。このようなときには， その正弦波成分を押觉るよらにプロセスの後と直交つ ィルタの前に適当なフィルタを入れ，雑音成分につい てのみ同定計算を行ならようにしなければならない。 このことは直流成分がある場合にも考慮しなければな らない、つぎに判定式 $D$ について考虑すると，これは $D \fallingdotseq 0$ となるものをプロセスの形として決定している のである。さきに述べた実験に执いては余裕があった

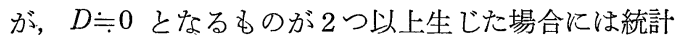
的な判定を行なわなければならない，本文では判定式 がひじょらに複雑なため統計的決定については議論し ていないが今後の重要な問題て)である.

\section{7. むす び}

以上，本論文では低次プロセスの同定とその形の決 定をオンラインで行なう方法を提案し，その誤差補正 について近似的な解析した。またパラメータの推定計 算は最急降下法によっているから収束を早くするため には定数を可変にすることも考光られるが，これにつ いては触れなかった。また，この方法は与兄られたプ ロセスをあらかじめ定めた低次数の伝達関数で近似す るときのパラメータ決定にも，すでに求められた計算 式をもらいて適用することができる。すでに述べたよ らに統計的決定の問題, 他の直交関数系を用いたとき の解析などいくつかの解決しなければならない問題が 残った．最後に日ごろ御討論いただく田中研究室の諸 氏，特に，大学院生田村進一君に感謝する。 


\section{参 考 文 献}

1）相良：同定問題，計測と制御，8-4，268/280 (1969)

2) T.Kitamori : Applications of Orthogonal Functions to the Determination of Process Dynamics Characteristics and to the Construction of SelfOptimizing Control, 1 st IFAC Moscow, 613/618 (1960)

古田：可变直交関数を用いた Process Identification, 計測と制御， 5-12，867/874 (1966)

3）茅：プロセス動特性の統計的推定，計測と制御， 6-4, 266/279 (1967)
4）桶口ほか：未知波形の適応同定，計測自動制御学会論 文集，5-2，127/133 (1969)

5）森下：未知信号を雑音から分離する適応ろ波器，計測 自動制御学会論文集, 1-3, 199/209 (1965)

6) L. A. Zadeh, et al. : Linear System Theory, p. 379 McGraw Hill (1963)

7）茅: 伝達関数のモデルの妥当性の検定，計測自動制御 学会論文集, 5-4, 348/357 (1969)

8) G. M. Roe, G. M. White : Probability Density Functions for Correlators with Noisy Reference Signals, IRE on IT, IT-7-1 (1961)

\section{第 6 巻 第 4 号 正 誤 表}

（栗林勝利・中島㪰男著「機械式無段変速機を使った On-Off 制御系の持続振動」）

\begin{tabular}{|c|c|c|c|c|}
\hline ページ & 欄 & 行 & 誤 & 正 \\
\hline 328 & 右 & 最下行 & 条件付安定と豆る. & 条件付安定となる. \\
\hline 331 & 左 & $\downarrow 15$ & 1) $\stackrel{4}{=}$. の仮定….... & 1) $\stackrel{3}{=}$. の仮定….... \\
\hline 331 & 左 & 最下行 & (ただし $\left(\dot{\theta}_{i}=\right.$ const. $)$ & (ただし ${\underline{\underline{\dot{\theta}_{i}}}}_{=}=$const. $)$ \\
\hline 332 & 左 & $(30 \mathrm{~b})$ 式中 & $+B n_{0}\left\{(t-\gamma)^{3} u \cdot(t-\gamma) \cdots \cdots\right.$ & $+B n_{0}\left\{(t-\gamma)^{3} \stackrel{\underline{u}}{=}(t-\gamma) \cdots \cdots\right.$ \\
\hline 332 & 左 & $(32 \mathrm{~b})$ 式中 & $\cdots-\frac{B n_{0} A^{2}}{2 \underline{\underline{B}}}$ & $-\frac{3 n_{0} A^{2}}{2 \underline{\underline{B}}}$ \\
\hline 333 & 右 & (43a) 式 & 右辺 $<\underline{=}$ & 右辺 $<-1$ \\
\hline 333 & 右 & $(43 b)$ 式 & 分母中 $\sqrt{\left(\gamma_{0} / 2-A / B+\dot{\theta}_{s} / B{\underline{\underline{\gamma_{0}}}}^{2}\right)^{2}-\cdots}$ & $\sqrt{\left(\gamma_{0} / 2-A / B+\dot{\theta}_{s} / B \underline{\underline{n_{0}}}\right)^{2}-}$ \\
\hline 334 & 左 & $\begin{array}{l}(45 \mathrm{a}) \text { 式の第 } \\
2 \text { 式の右边 }\end{array}$ & $\left\{1-\left(2+3 \beta_{0} / \delta_{0}\right)(\cdots\right.$ & $\left\{1-\left(2+3 \beta_{0} \mid \underline{\underline{r}}_{0}\right)(\cdots\right.$ \\
\hline 334 & 左 & $\begin{array}{l}(45 \mathrm{~b}) \text { 式の左辺 } \\
\text { 第 } 1 \text { 項の分子 }\end{array}$ & $\left\{\dot{\theta}_{i}-B n_{0}\left(\frac{A}{B}-\frac{r_{0}}{2}\right\}^{2}\right.$ & $\left\{\theta_{i}-B n_{0}\left(\frac{A}{B}-\frac{r_{0}}{2}\right)\right\}^{2}$ \\
\hline 335 & 左 & $\downarrow 6$ & $\dot{\theta}_{i d}<\dot{\theta}_{1}<\dot{\theta}_{\underline{\underline{i c}}}, \cdots \cdots$ & $\dot{\theta}_{i d}<\dot{\theta}_{1}<\dot{\theta}_{\underline{\underline{i f}}}, \cdots \ldots$ \\
\hline " & 右 & Fig. 11 (a) & $\stackrel{\dot{\theta}}{=}=0.151[\mathrm{rad} / \mathrm{s}]$ & $\stackrel{\underline{\underline{\theta_{1}}}}{=}=0.151[\mathrm{rad} / \mathrm{s}]$ \\
\hline " & 右 & Fig. 11 (b) & $\underline{\underline{\theta_{1}}}=0.064[\mathrm{rad} / \mathrm{s}]$ & $\stackrel{\dot{\theta}_{1}}{=}=0.064[\mathrm{rad} / \mathrm{s}]$ \\
\hline " & 右 & Fig. 11 (c) & $\underline{\underline{\theta_{1}}}=0.0955[\mathrm{rad} / \mathrm{s}]$ & $\underline{\underline{\dot{\theta}_{1}}}=0.0955[\mathrm{rad} / \mathrm{s}]$ \\
\hline 336 & 左 & $\downarrow 5$ & 巻き纪巻き径の...... & 巻きによる巻き径の…… \\
\hline
\end{tabular}

